\title{
Correction to: Estimation of coda Q for the eastern Indian craton
}

\author{
Koushik Biswas ${ }^{1, *}{ }_{(\mathbb{D})}$, Prantik Mandal $^{2}$ and Prosanta Kumar Khan ${ }^{3}$ \\ ${ }^{1}$ Oil and Natural Gas Corporation Limited, Dehradun, Uttarakhand 248 195, India. \\ ${ }^{2}$ National Geophysical Research Institute (CSIR), Uppal Road, Hyderabad 500 00\%, India. \\ ${ }^{3}$ Indian Institute of Technology (Indian School of Mines), Dhanbad 826 004, India. \\ *Corresponding author. e-mail: koushik.biswas59@gmail.com
}

published online 28 May 2019

Correction to: J. Earth Syst. Sci. (2019) 128:109; https://doi.org/10.1007/s12040-019-1140-7

In the original version of this article, third author's affiliation was incorrectly represented. The corrected affiliation is given below.

Prosanta Kumar Khan

Indian Institute of Technology (Indian School of Mines), Dhanbad 826 004, India. 